\title{
The Effects of Welding Processes on Microstructure and Abrasive Wear Resistance for Hardfacing Deposits
}

\author{
K.M. KenchiReddy and C.T. Jayadeva
}

\begin{abstract}
In this study, two different electrodes were used to examine the effect of microstructure and wear resistance for hardfacing deposits. Electrode-1 has less wear as compared to electrode-2 as the percentage of chromium, carbon and silicon is more in electrode-I. The factors such as, arc current, arc voltage, welding speed, electrode stick-out and preheat temperature predominantly influence the weld quality. The abrasion tests were conducted on a dry sandrubber wheel abrasion machine as per ASTM G65 standard. Results revealed that as hardness increases, the loss of wear decreases. The wear surface results were analyzed by scanning electron microscopy results which indicates that the best abrasion resistance is obtained in microstructures composed of chromium carbide alloy.
\end{abstract}

Keywords--- Hardfacing Alloys, Three-Body wear, Microstructure, Wear Mechanisms, Abrasion Resistance

\section{INTRODUCTION}

$\mathrm{T}$ HE prime requirement of a metal is to have a good resistance to wear, corrosion and high temperature. Hardfacing is a low cost method of depositing wear resistant surfaces on metal components to extend service life. A wide variety of hardfacing alloys are commercially available for protection against wear and selecting the best suited for a particular application is very essential. The composition of the deposit will depend upon the base metal composition and dilution. Base metal composition is very significant in determining the preheating temperature. Carbon and low-alloy steels with carbon content of less than one percent can be easily hardfaced whereas high-carbon steel may require a special buffer layer. Selection of an alloy also depends on the nature of the service creating the need for hardfacing.

Various surface alloys are available in different forms such as, bare welding rods, electrodes, and coiled wires and also in the form of powders [1]. It serves satisfactorily in certain conditions depending upon its composition, microstructure of the deposited layer and its hardness.

$\mathrm{Fe}-\mathrm{Cr}$ - $\mathrm{C}$ alloys are used in severe conditions where there is extreme erosion and therefore abrasion resistance is necessary. Their exceptional abrasive and erosive wear resistance results

K.M. Kenchi Reddy, Research Scholar, Department of Mechanical Engineering, Dr. T. Thimmaiah Institute of Technology, KGF, India. Email:kenreddy@rediffmail.com

C.T. Jayadeva, Professor, Department of Mechanical Engineering, Adichunchanagiri Institute of Technology, Chikmagalur, India. E-mail: ctjayadeva@yahoo.co.in primarily from their high volume fraction of hard carbides, though the toughness of the matrix also contributes to the wear resistance. The investigations of $\mathrm{Fe}-\mathrm{Cr}-\mathrm{C}$ alloy microstructures have shown that these types of materials have hypoeutectic, eutectic, and hypereutectic structures [2]. The hardfacing alloys obtained using high-energy density sources such as electron beam welding; plasma arc and laser have been widely applied to enhance the wear and corrosion resistance of material surface [3]. In this study two different hardfacing alloys were used for overlaying. These are basically iron based alloys having varying amount of chromium, carbon and other alloying elements as they are more suitable for low stress abrasive wear condition $[4,5,6]$. Results revealed that weld metal chemistry and hardness have significant influence on wear property.

\section{LITERATURE REVIEW}

An extensive literature review was carried out on hardfacing materials. The important base metals for hardfacing are stainless steel, manganese steel, mild steel, nickel base and copper base alloys. Various methods are available for hardfacing and selecting the best suited method for particular application is very essential. In this direction, different materials used for hardfacing, its purposes and recent innovations have been identified [7, 8]. Various techniques are available for hardfacing $[9,10,11]$. After thorough investigation on these methods the best suited process SMAW was selected for the research work. From the literature study, it is observed that, the common materials used for hardfacing and their purpose is presented in table 1.

The welding processes determine the filler metal form and deposition efficiency. Arc welding processes are generally preferred for hardfacing for reasons of speed and low cost. Before selecting a welding process, importance is given to position of welding, base metal dilution, deposition rate and other process capabilities [12, 13]. The deposition rates of different welding processes are given in table 2. From the table it is evident that, FCAW has highest deposition rate among all common processes. FCAW is used for all overlaying, hardfacing and cladding applications. Typical application areas include extruding machine screws, valves, valve seats of internal combustion engines, accessories of ships, power generation, cutting tools, process equipments in ceramics and cement production, moulds and forging dies, agricultural equipments and parts for nuclear power plants[14,15,16]. 
Table 1: Materials used for Hardfacing

\begin{tabular}{|c|c|}
\hline Metal Alloy & Purpose \\
\hline Cobalt-base alloys & Wear and corrosion resistance \\
\hline Copper-base alloys & Rebuilding worn machinery parts \\
\hline Iron-chromium alloys & High stress abrasion \\
\hline Manganese steel & Wear application \\
\hline Nickel-base alloys & Tooling, Wear application \\
\hline Tools steel & High stress abrasion \\
\hline Tungsten carbide & \\
\hline
\end{tabular}

Table 2: Deposition Rates of Different Welding Processes

\begin{tabular}{|c|c|}
\hline Process & Deposition Rates (Kg/Hr) \\
\hline Flux core arc welding (FCAW) & $3.63-11.34$ \\
\hline Gas metal arc welding (GMAW) & $2.3-5.44$ \\
\hline Gas tungsten arc welding (GTAW) & $1.4-2.3$ \\
\hline Shielded metal arc welding (SMAW) & $1.4-2.3$ \\
\hline Submerged arc welding (SAW) & $3.63-11.34$ \\
\hline Oxy fuel arc welding (OFW) & $2.3-4.54$ \\
\hline
\end{tabular}

Table 3: Chemical Composition of Base Metal (in Weight Percentage)

\begin{tabular}{|c|c|c|c|c|}
\hline $\mathrm{C}$ & $\mathrm{Si}$ & $\mathrm{Mn}$ & $\mathrm{S}$ & $\mathrm{p}$ \\
\hline 0.18 & 1.47 & 0.32 & 0.013 & 0.029 \\
\hline
\end{tabular}

Table 4: Chemical Composition of Hardfacing Alloy (In weight Percentages)

\begin{tabular}{|c|c|c|c|c|c|c|c|c|c|}
\hline Electrode & $\mathrm{C}$ & $\mathrm{Si}$ & $\mathrm{Mn}$ & $\mathrm{S}$ & $\mathrm{p}$ & $\mathrm{Cr}$ & $\mathrm{Mo}$ & $\mathrm{Ni}$ & $\mathrm{V}$ \\
\hline Hardfacing 1 & 0.33 & 0.28 & 1.15 & 0.014 & 0.025 & 2.22 & - & - & - \\
\hline Hardfacing 2 & 0.1 & 0.38 & 1.51 & 0.024 & 0.03 & 2.15 & 0.745 & 1.09 & 0.103 \\
\hline
\end{tabular}




\section{EXPERIMENTAL DETAILS}

\section{A. Base Metal}

The selection of base metal is very essential in deciding what alloy to use for hardfacing deposit. Since welding procedure differs according to the base metal. The base metal selected for this study is mild steel which composes the main elements of carbon, silicon, manganese, sulphur, and phosphorous. The chemical composition is given in table 3 .

\section{B. Hardfacing Alloys}

Two different commercial hardfacing alloys were used for overlaying. These are basically iron - based alloys having varying amount of chromium, carbon, silicon and other alloying elements as they are more suitable for shielded metal arc welding process. Chemical compositions of two electrodes are presented in table 4.

\section{Welding Conditions}

The standard size test specimens of 16 nos. with the dimensions of $250 \times 100 \times 12 \mathrm{~mm}$ were selected for the experiment. The following precautions are taken before hardfacing.

- The electrodes are perfectly dried in the furnace and baked at $250^{\circ} \mathrm{C}$ one hour before the use

- Area of the weld is properly cleaned

- Preheated the hardfacing area to a minimum of $200^{\circ} \mathrm{C}$

\section{Methodology}

The experiment was carried out in three stages to investigate the effect of current, travel speed and voltage on hardfacing electrodes, and the corresponding hardness was determined.

1) In first stage, voltage (V) and travel speed (S) were kept constant and current (A) was increased.

2) In second stage, voltage (V) and current (A) were kept constant and travel speed (S) was increased.

3) In third stage, current (A) and travel speed (S) were kept constant and voltage (V) was increased

\section{Microstructure AnALYsis}

Optical microscope (OM) was used to analyze the microstructure of the specimens. Different types of carbides present in the microstructures were first identified on the basis of their morphologies and confirmed by micro-hardness measurements. Typical microstructures of weld deposits made with different welding parameters illustrates that the low, medium and high wear resistance shown in figures 1(a) to 3(b). This microstructural characteristics are reflected in the hardness values (table 4), higher amount carbide and finer structure, in general, resulted in higher hardness, whereas lower hardness values were recorded in weld deposits with less amount of carbide and coarser structure. The microstructure clearly indicated that, the wear track will be small and narrow indicates there will be less in wear and wear resistance is increase from specimen 3 to 5 (fig 2(a) to 3(b). Also results indicate that the wear resistance increases with increasing hardness. The wear loss will be 1.6075 grams for the specimen 1 which is at $377 \mathrm{Hv} 05$ is decreased by 0.6007 of the specimen 5 which is hardness $418 \mathrm{HV}$. It is clearly observed both from wear results and microstructures. The wear resistance increased by 62 percent by varying welding current and travel speed and keeping welding parameters is constant.

\section{A. Microstructures of Different Hardfacing Deposits}

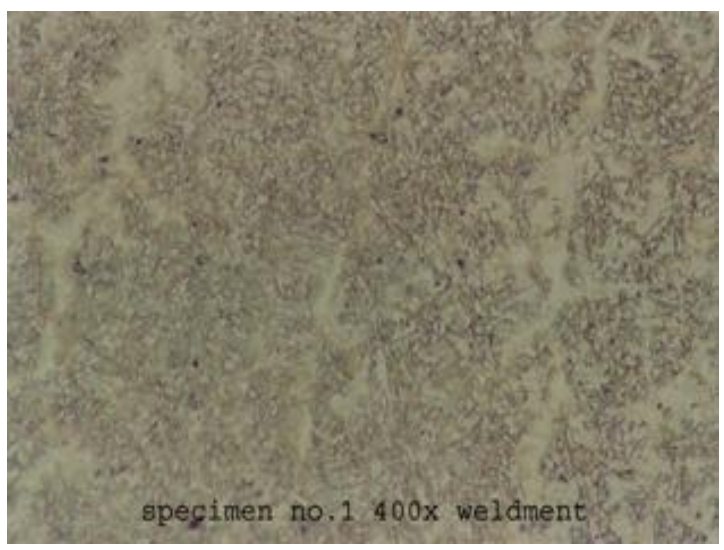

Figure 1: (a)

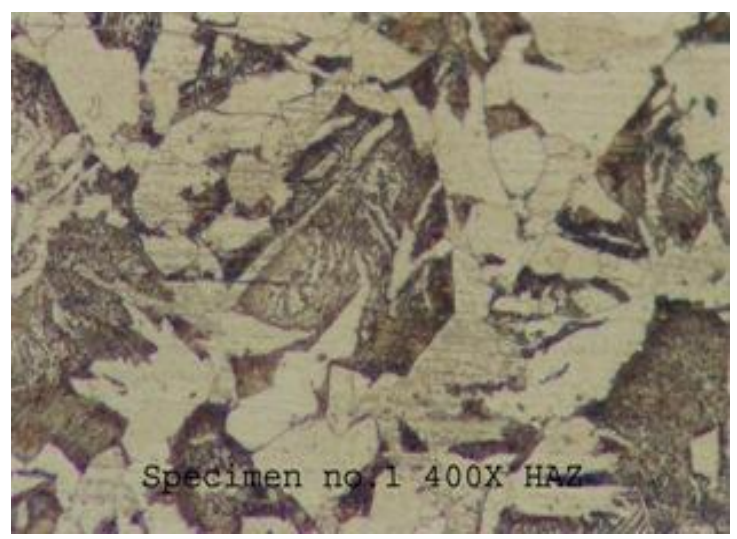

Figure 1: (b)

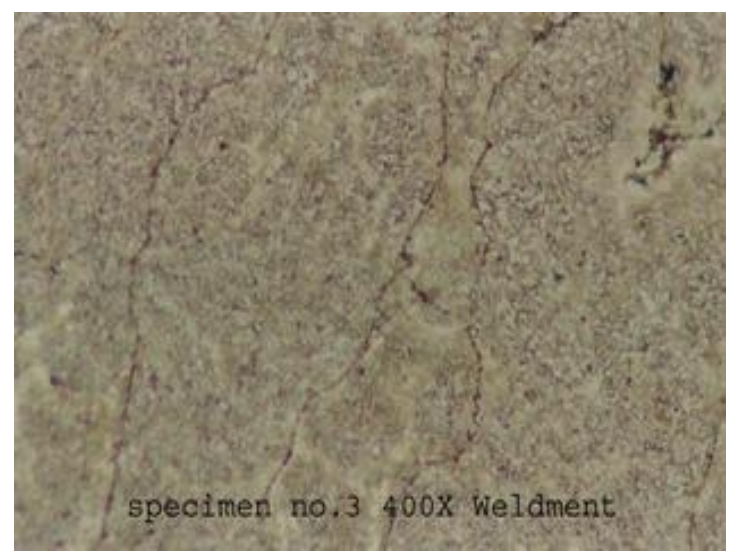

Figure 2: (a) 


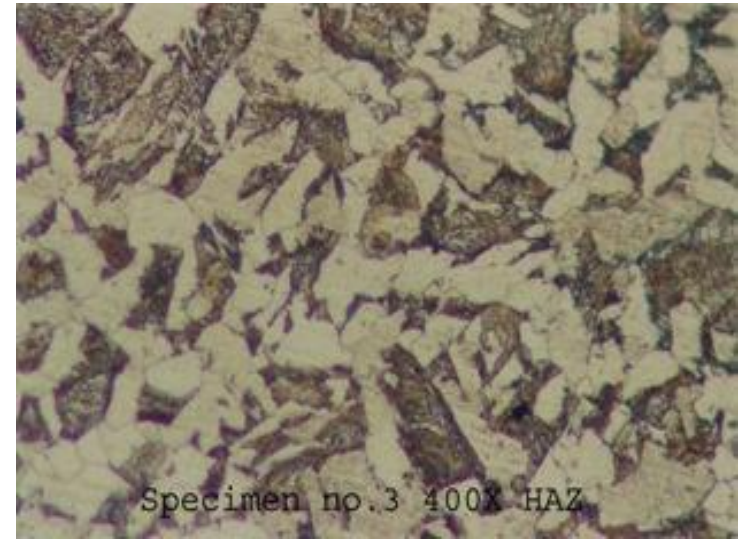

Figure 2: (b)

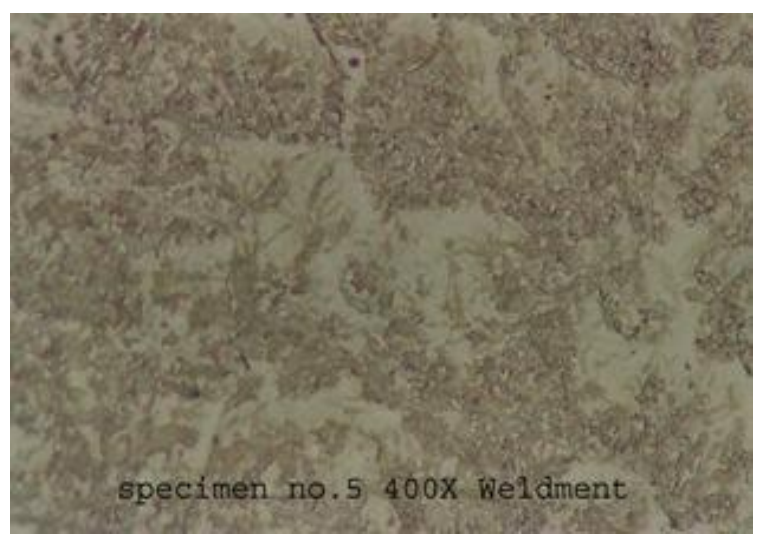

Figure 3: (a)

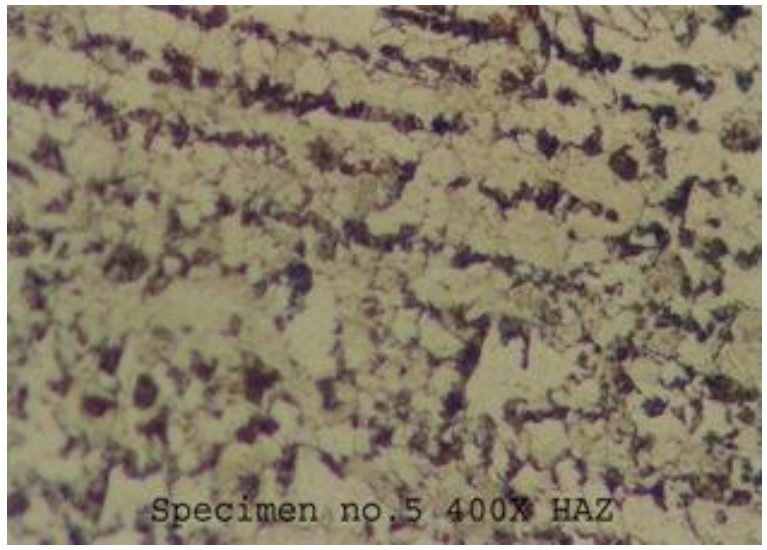

Figure 3: (b)

In fig 1(a) \& (b), the amount of ferrite and Pearlite is more hence resulting in lower hardness and wear resistance. In fig 2(a) \& 2(b) the amount of ferrite and pearlite is medium hence moderate hardness and wear resistance. In fig 3(a) \& (b), the structure consists martensite with retained austenite and patches of pearlite distributed uniformly.

\section{B. Scanning Electron Micrographs}

The photographs for the specimens 1, 3and 5 after dry sand abrasion test through SEM are shown in figures 4, 5 and 6. The worn out specimens consists of low, medium and high abrasion resistance at the entry and exit. Examination of the wear scars indicate that morphologies for all the samples were similar consisting of three zones, a short entrance and exit area and the main wear zone in middle. At the entrance and exit zones where the pressure applied to the abrasive is lowest the damage morphologies were consistent with particle rolling. In the centre of wear scar, parallel grooves were formed, typical of particle sliding, a result of the higher pressures forcing abrasives in to rubber wheel. The worn surfaces are characterized by shallow continuous grooves and micro cuttings in sample in fig 6 (a) \& (b) indicating that material removal is associated primarily with ploughing mechanism. The fine grained silica sand corresponds to low wear level where as the high energy level of coarse corundum particles is resulting in a severe wear region abrasion test were carried out on a dry sand rubber wheel with three body abrasion condition under low stress according to ASTM G65 procedure A. rotational speed, normal load work kept constant at $200 \mathrm{rpm}$ and $130.5 \mathrm{~N}$ respectively, characterization of microstructure has been done with optical microscopy and scanning electron microscopy quantitative analysis of the microstructure was carried out by the use of intronic image $\mathrm{C}$ software. Hardness measurements were carried out with a standard Vickers hardness technique HV0.5 for microscopic hardness. Quantitative wear characterization has been done by gravimetric mass loss of the testing specimen during wear testing. Qualitative characterization of worn surfaces and worn edges has been carried out by evaluating of macroscopic and cross section images and by SEM investigations. The sample numbers \& its relation between hardness and abrasion resistance is shown in table 5 .

\section{RESUlTS AND DISCUSSION}

The typical microstructure of the studied hardfacing alloys are shown in figures 4,5 and 6 . The worn surfaces were observed under SEM and secondary electrons were used to analyze these surfaces, to establish the possible mechanisms of material removal. In Figure 4, the surface wear is presented for all the three hardfacing alloys. Figure 4 shows, wear loss increases with the abrading distance and demonstrate that sample 1 wear loss is higher than that of sample 5, suggesting that carbides indeed have a reinforcing effect.

Figures 4 (a) \& (b) shows the worn surface features of sample 1 , where micro-ploughing and micro-cutting are the main abrasive wear mechanisms. Figure 5 (a) \& (b) indicate the surface of sample 3, where micro-cutting and wedge formation were the main abrasive mechanisms. The worn surface of samples 1 and 3 clearly shows obvious evidence of cutting and ploughing (Fig. 4 and 5). However, no obvious plastic deformation can be found on the worn surface of sample 5 (Fig. 6) although there are some slight traces of ploughing to be seen on the matrix area, these cease when elements such as carbides are encountered, indicating that the silica and chromium elements effectively stop the abrasive form cutting or ploughing into the surface layer during the wear process, thereby noticeably lowering the wear loss. However, the grooves were not deeper than samples 1 and 3; this hardfacing deposit presented higher abrasion resistance, because the large quantity of carbides rich in titanium, uniformly distributed in the matrix, blocked the abrasive particles. Further, the resistance of silica, manganese and chromium elements to the abrasive could be attributed to its 
higher hardness. Further observations of figure 6 also provide evidence of cutting and cracking of the carbides. It is reasonable to believe that the wear resistance of the materials will increase if the hardness of the hardfacing alloy is improved.

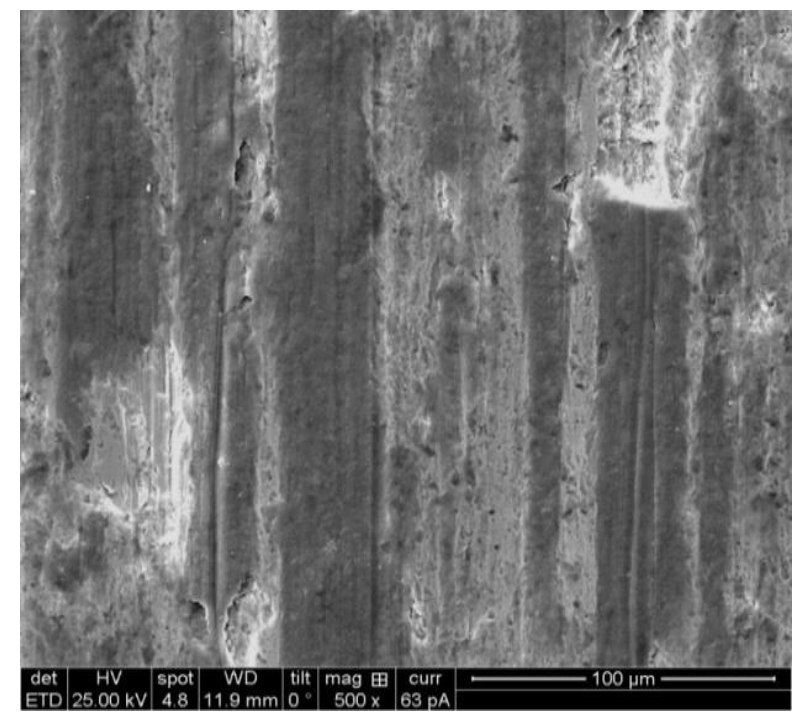

(a) $15 \mathrm{~min}$

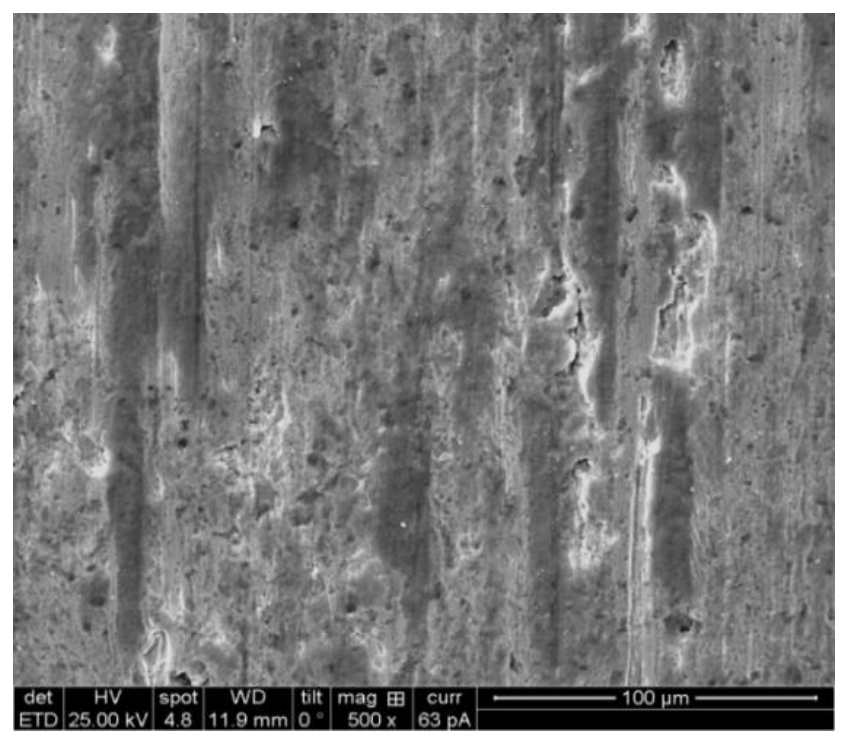

(b) $30 \mathrm{~min}$

Figure 4: Worn Surface Features of Sample 1

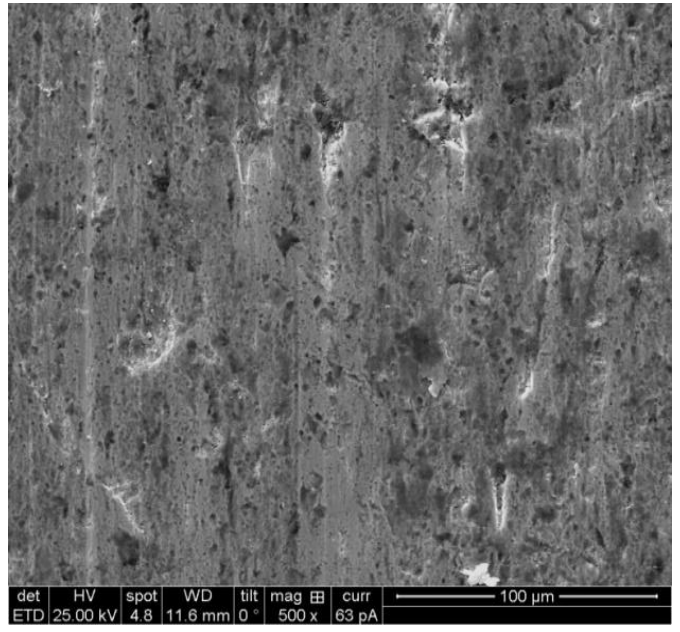

(a) $15 \mathrm{~min}$

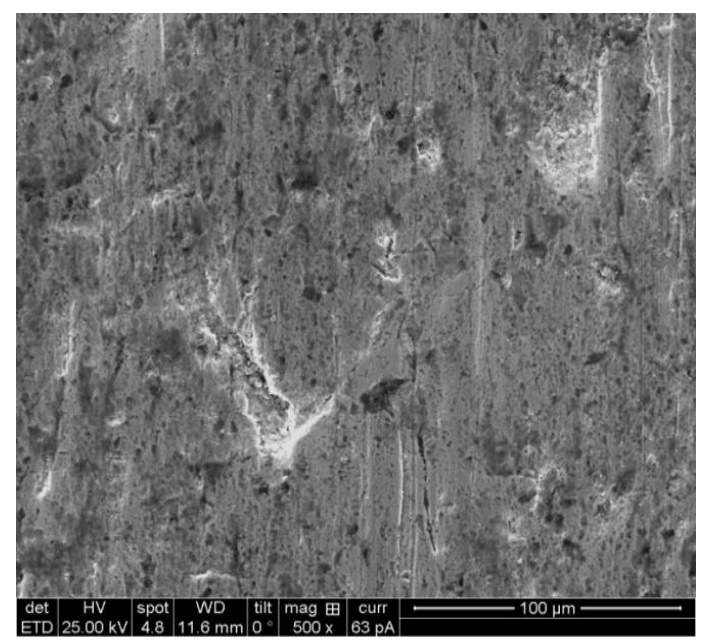

(b) $30 \mathrm{~min}$

Figure 5: Worn Surface Features of Sample 3

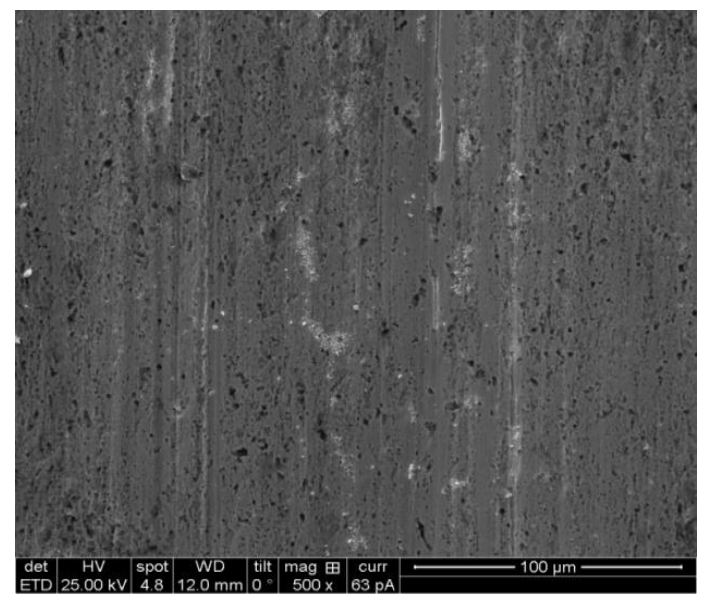

(a) $15 \mathrm{~min}$ 


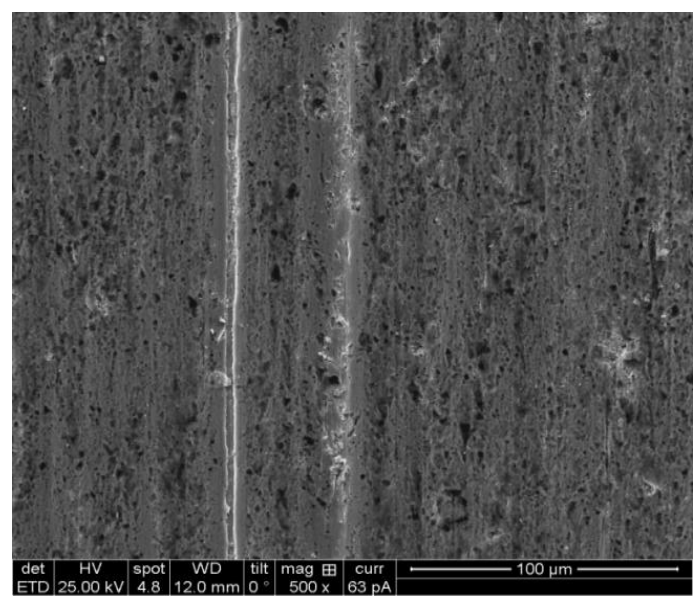

(b) $30 \mathrm{~min}$

Figure 6: Worn Surface Features of Sample 5

Table 5: The relation between Hardness and Abrasion Resistance

\begin{tabular}{|c|c|c|c|}
\hline Sample Number & Load $(\mathrm{N})$ & Weight Loss (g) & Hardness (HV 0.5) \\
\hline 1 & 130.5 & 1.6075 & 377 \\
\hline 2 & 130.5 & 1.3345 & 318 \\
\hline 3 & 130.5 & 0.9861 & 380 \\
\hline 4 & 130.5 & 0.638 & 417 \\
\hline 5 & 130.5 & 0.6007 & 418 \\
\hline 6 & 130.5 & 0.8454 & 356 \\
\hline 7 & 130.5 & 1.0923 & 537 \\
\hline 8 & 130.5 & 0.5934 & 390 \\
\hline 9 & 130.5 & 0.9051 & 330 \\
\hline 10 & 130.5 & 0.9698 & 416 \\
\hline 11 & 130.5 & 0.9746 & 370 \\
\hline 12 & 130.5 & 0.9205 & 406 \\
\hline 13 & 130.5 & 1.1571 & 388 \\
\hline 14 & 130.5 & 1.0576 & 377 \\
\hline 15 & 130.5 & 0.9852 & 357 \\
\hline 16 & 130.5 & 0.9506 & 401 \\
\hline
\end{tabular}




\section{CONCLUSIONS}

Three-body abrasive wear tests were conducted to investigate the effect of abrading distance, composition and welding parameters of hardfacing alloys. A wealth of information was obtained based on experiments. The results can be summarized as follows:

- Abrading distance exerted the greatest effect on the abrasive wear followed by hardfacing carbides. The load applied has a much lower effect.

- In addition, hardfacing elements such as chromium, carbon, silicon, manganese, sulphur, and phosphorous improved the wear resistance of the hardfacing alloy. Wear loss increased with load applied.

- The principle of wear mechanism was micro-cutting and micro-ploughing in hardfacing alloys, except the fracturing accompanied by elements such as chromium, carbon, silicon, manganese, sulphur, and phosphorous increasing the hardness of hardfacing alloy could improve wear resistance.

\section{REFERENCES}

[1] Ravi Menon, New Developments in hardfacing Alloys, Welding Journal, Pp. 61-67, February 1996.

[2] Eroglu, M, Ozdemir, N, Surf. Coat. Techno 154, pp209, 2002.

[3] Lu L, H. Soda, A. McLean, Material Science Engineering, A 347, Pp. 214, 2003.

[4] Dasgupta R ,'Surface Engineering- An Avenue for ImprovingLife of Agricultural Implements", IE (I) Journal-MM, Vol.79, Pp. 36-43, 1998.

[5] Fominskii L.P, Hardfacing working components of agricultural machines using an electron accelerator, Welding International, 12, Pp. 1110-1113, 1998.

[6] Kotecki D. J and Ogborn J. S, "Abrasion Resistance of Iron-Based Hardfacing Alloys", Welding Journal, Pp. 269-278, 1995.

[7] Buchely, M.F., Gutierrez, J.C., León, L.M. and Toro, A. "The effect of microstructure on abrasive wear of hardfacing alloys", Wear, Vol. 259, Issues 1-6, Pp. 52-61, 2005.

[8] Seon-Jin Kim, Young-Min Oh, Jun-Gi Kim, "Fe-Based Hardfacing Alloy", United States Patent Publication, Pub. No.: US 2005/0139294 A1,2005.

[9] Vernon E. Buchanan, "Solidification and microstructural characterisation of iron-chromium based hardfaced coatings deposited by SMAW and electric arc spraying", Surface and Coatings Technology, Vol. 203, Issue 23, Pp. 3638-3646, 2009.

[10] Xin-hong Wang, Fang Han, Shi-yao Qu, Zeng-da Zou, "Microstructure of the Fe-based hardfacing layers reinforced by TiC-VC-Mo2C particles", Surface and Coatings Technology, Vol. 202, Issue 8, Pp. 1502-1509, 2008.

[11] Xinhong Wang, Fang Han, Xuemei Liu, Shiyao Qu, Zengda Zou, "Microstructure and wear properties of the $\mathrm{Fe}-\mathrm{Ti}-\mathrm{V}-\mathrm{Mo}-\mathrm{C}$ hardfacing alloy", Wear, Vol. 265, Issues 5-6, Pp. 583-589, 2008.

[12] Qian Ming, L. C. Lim, Z. D. Chen, "Laser cladding of nickel-based hardfacing alloys", Surface and Coatings Technology, Vol. 106, Issues 2-3, Pp. 174-182, 1998.

[13] S. Chatterjee, T.K. Pal, "Wear behavior of hardfacing deposits on cast iron", Wear, 255, Pp. 417-425, 2003.

[14] W. Wo, L.-T. Wu, "The wear behavior between hardfacing materials", Metall. Mater. Trans. A 27A , Pp. 3639-3648, 1996.

[15] L.P. Fominskii, "Hardfacing working components of agricultural machines using an electron accelerator", Welding International, 12, Pp. 1110-1113, 1998.

[16] Horsfield, A. M., Weld Surfacing and Hardfacing, The Welding Institute, Abington Hall, Pp. 32 - 39, 1980.

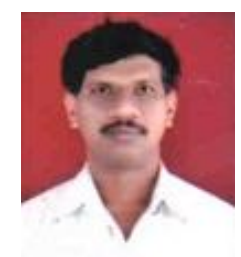

C.T. Jayadeva is born in Karnataka, India on $18^{\text {th }}$ July 1963. He earned his Undergraduate degree in Industrial and Production Engineering in 1986 from University of Mysore, Karnataka, Postgraduate degree in Industrial Engineering from university of Calicut, Kerala in the year 1993 and $\mathrm{Ph}, \mathrm{D}$ in Quality Management from VTU, Belgaum, India in the year 2008. He worked as Principal at Yagachi Institute of Technolgy, Hassan, Karnataka and presently working as Professor in the Department of Mechanical Engineering, AIT, Chikmaglur, Karnataka, He has published 24 papers in National/International conferences/journals. He is a Life Member of Indian Society for Technical Education.

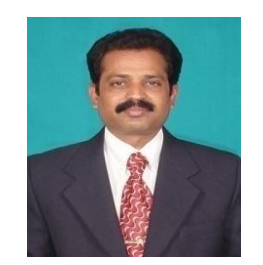

K. M. Kenchi Reddy is born in Karnataka, India on $4^{\text {th }}$ August 1961. He earned his Undergraduate degree in Mechanical Engineering in 1986 from University of Mysore, Karnataka, India, Postgraduate degree in Production Engineering and Technology from Mysore University in the year 1994 and presently working as Assistant Professor in the Department of Mechanical Engineering, Dr T Thimmaiah Institute of Technology, KGF. He has published 8 papers in National/International conferences/journals. He is a Life Member of Indian Society for Technical Education 